\title{
Effect of Heat Treatment on Properties of INCONEL 617 Investigated in Accelerated Creep Testing
}

\author{
Noppakorn Phuraya ${ }^{1, \mathrm{a}}$, Isaratat Phung-on ${ }^{2, \mathrm{~b}, *}$, and Jongkol Srithorn ${ }^{3, \mathrm{c}}$ \\ 1 Department of Production Engineering, Faculty of Engineering, King Mongkut's University of \\ Technology Thonburi, Bangkok 10140, Thailand \\ 2 Maintenance Technology Centre, ISTRS, King Mongkut's University of Technology Thonburi, Bangkok \\ 10140, Thailand \\ 3 School of Industrial Engineering, Faculty of Engineering, Suranaree University of Technology, Nakhon \\ Ratchasima 30000, Thailand \\ E-mail: apaeasus@gmail.com, bisa_ceo@yahoo.com (Corresponding author), and cjongkol@sut.ac.th
}

\begin{abstract}
An accelerated creep test was implemented to study the effects of heat treatment on the creep properties of INCONEL 617. Three heat treatment conditions were set on the test specimens, including 1) as-received, 2) aged as the simulation of service conditions at $650^{\circ} \mathrm{C}$ for $1,000 \mathrm{~h}$ and 3) solutionised. The accelerated creep test was performed at $700,750,800$ and $900^{\circ} \mathrm{C}$ with applied stress at $80 \%$ and $90 \%$ of the yield stress (YS) at tested temperatures. The results were analysed for both time to rupture and \% RA, which showed that there was a significant drop in time to rupture and $\% \mathrm{RA}$ at $750^{\circ} \mathrm{C}$. Subsequently, the $\%$ RA increased while the time to rupture gradually decreased. The Larson Miller curve for all heat treatment conditions could be plotted with an interest in the presence of an intersection zone. This indicated the possibility of failure behaviour changes from a creep mode to an overload mode at low applied loads to high applied loads, respectively.
\end{abstract}

Keywords: INCONEL 617, Creep test, $\mathrm{Cr}_{23} \mathrm{C}_{6}$-type carbides.

ENGINEERING JOURNAL Volume 21 Issue 5

Received 27 December 2016

Accepted 28 March 2017

Published 29 September 2017

Online at http://www.engj.org/

DOI:10.4186/ej.2017.21.5.273 


\section{Introduction}

Inconel 617, a solid solution nickel-based superalloy, has been widely used in high-temperature environments due to its excellent high-temperature strength, sufficient metallurgical stability, good resistance to creep, and superior resistance to corrosion and oxidation. [1-3]. It is well-known that $\mathrm{M}_{23} \mathrm{C}_{6}$ carbide network is formed along grain boundaries during long-term exposure at elevated temperature. This affects creep performance of this alloy. [4].

Study of creep performance is the major issue for operation of components exposed to high temperatures and pressures in power generating industries. Generally, the creep test is assessed thought creep test classified as long term and short term. Long-term creep test required testing time up to $100,000 \mathrm{~h}$ which is to long practice in laboratories. On the other hand, short-term testing, typically called stress rupture [5-7], is taken less than 1,000 h, and flexible for experiment. The result of testing in creep test is emphasized on strain rate, while stress rupture is focused on time to failure. In addition, the damage and failure mechanisms in the short-term tests are different from long-term tests. Care is taken to prevent misleading in interpretation of the creep life due to the possible changes in microstructures [7-8]. Several methodologies, such as Larson-Miller Parameter (LMP), Manson-Sucoop parameter and Wilshire method [5], to study the creep life of alloys have been suggested by researchers using short-term creep-test data. According to previous investigated of creep behaviour of Inconel 617 pipes for power plant [6], the Larson-Miller Parameter (LMP) technique is widely used to predict the creep life of high temperature materials due to its simplicity of application [6].

Previously, the effects of heat treatment process on creep performance of Inconel 617 have been investigated. Md. S. Rahman et al. [1] studied the creep performance of Inconel 617 in solution annealed condition at $1,180^{\circ} \mathrm{C}$ for $1 \mathrm{~h}$ followed with creep testing at 600 and $800^{\circ} \mathrm{C}$. The results indicated that the elongation decreased with increasing in the temperature. At $800^{\circ} \mathrm{C}$, the formation of $\mathrm{M}_{23} \mathrm{C}_{6}$ precipitates was observed. This impeded the dislocations movement. M. Akbari-Garakani et al. [2] reported the formation of continuous network of $\mathrm{M}_{23} \mathrm{C}_{6}$ carbides along grain boundaries on exposed materials which facilitated grain boundary sliding easily and resulted in a decreased creep life compared to new materials. M. Cabibbo et al. [3] also observed similar type of the $\mathrm{M}_{23} \mathrm{C}_{6}$ carbides along grain boundaries which contribute to the formation of film morphology. Then, grain boundary sliding occurred and caused creep rupture. In summary, the presence of continuous carbide network along grain boundaries had great influence on creep performance of this alloy. However, there is no information providing a full explanation of microstructure development concerned creep performance of Inconel 617 specimens similar to the real operation of the components used in industries. An experimental study, covering a series of the short-term tests and microstructure analyses for a set of material and several repaired conditions, is demanded to understand the relationship at service temperatures.

In this study, the effect of microstructural takes place in each heat treatment conditions among the asreceived, -aged, and -solutionised specimens are explored in order to assess the creep life using the LMP values.

\section{Experiment}

\subsection{Material and Test Specimen Preparation}

The investigated material was INCONEL 617, which contains the chemical composition shown in Table 1. Three heat treatment conditions were used to study the as-received (AS), aged (AG) and solutionised (SO) specimens, as shown in Table 2 .

\subsection{Testing Procedures}

\subsubsection{Elevated temperature tensile test (preliminary test)}

For the elevated temperature tensile test, specimens were machined into rectangular shapes, as shown in Fig. 1(a). Elevated temperature tensile tests were carried out at a constant testing speed of $3 \mathrm{~mm} / \mathrm{min}$ and at tested temperatures of $700,750,800$ and $900^{\circ} \mathrm{C}$. The elevated temperature tensile test was performed 
using a universal testing machine with heating application. The temperatures were controlled within $\pm 5^{\circ} \mathrm{C}$ of the set point using a PID temperature controller.

\subsubsection{Creep rupture test}

Creep rupture test specimens were machined to a rectangular shape, as shown in Fig. 1(b). The creep rupture test was conducted using a creep test machine at King Mongkut's University of Technology Thonburi (KMUTT) for tested temperatures of $700,750,800$ and $900^{\circ} \mathrm{C}$ under constant stress at $80 \% \mathrm{YS}$ and $90 \% \mathrm{YS}$, as taken from the previous step. The tested temperatures were controlled within $\pm 2{ }^{\circ} \mathrm{C}$ [9] by monitoring with K-type thermocouples attached to the middle of the specimens. The time taken to failure was recorded for each specimen. The reduction of area as a function of ductility was measured and the Larson-Miller Parameter (LMP) curve was created for the AS, AG and SO conditions to predict the time to rupture.

Table 1. Chemical composition (wt \%) of INCONEL 617 as measured by a spectrometer.

\begin{tabular}{cccccccccccc}
\hline Alloy & Ni & Cr & Fe & C & Mn & Si & Co & Mo & Al & Ti & P \\
wt $\%$ & 66.43 & 15.11 & 0.50 & 0.10 & 0.08 & 0.06 & 11.54 & 4.30 & 1.51 & 0.27 & 0.01 \\
\hline
\end{tabular}

Table 2. Three material conditions of INCONEL 617.

ID

Heat treatment condition

\begin{tabular}{ll}
\hline As Received (AS) & None \\
Aged (AG) & $650^{\circ} \mathrm{C}$ for $1,000 \mathrm{~h}$ and furnace cooled \\
Solutionised (SO) & $650^{\circ} \mathrm{C}$ for $1,000 \mathrm{~h}+1,175^{\circ} \mathrm{C}$ for $1 \mathrm{~h}+$ water quench \\
\hline
\end{tabular}

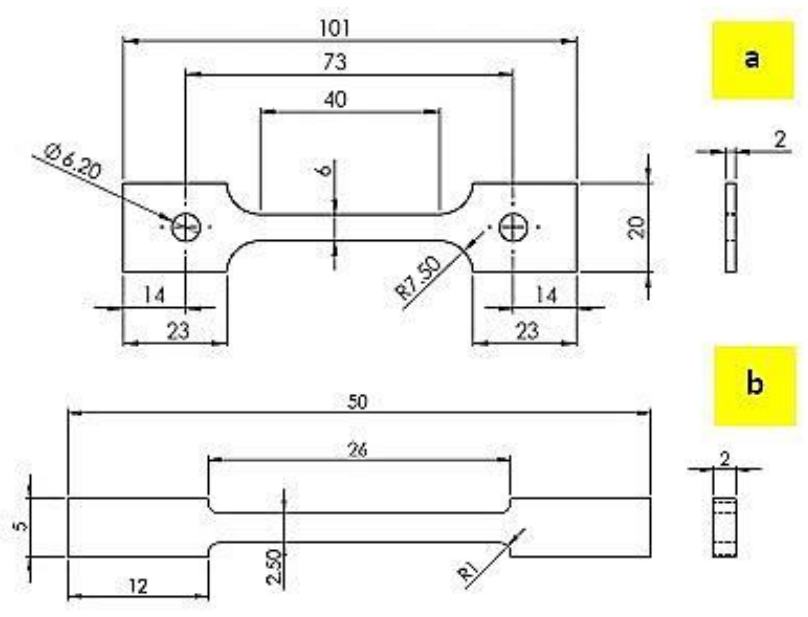

Fig. 1. Specimen geometry in different dimensions for (a) the elevated temperature tensile test specimen, and (b) the creep rupture test specimen.

\subsection{Metallographic Examination}

A metallographic examination was carried out prior to the elevated temperature tensile test and after the creep test using both optical microscopy (OM) and scanning electron microscopy (SEM) to characterise the presence of microvoids and precipitate phases. An energy-dispersive spectroscopy (EDS) was performed in order to determine the alloying composition of the precipitate phase. X-ray diffractometry (XRD) was utilised to characterise the phases in the alloy after the creep test. 
Metallographic samples were sectioned from the creep specimens using a cut-off wheel, which were then mounted in Bakelite resin and polished. The specimens were etched using a solution consisting of 2 grams of cupric chloride $\left(\mathrm{CuCl}_{2}\right), 40 \mathrm{ml}$ of hydrochloric acid $(\mathrm{HCl})$ and $80 \mathrm{ml}$ of methanol $\left(\mathrm{CH}_{3} \mathrm{OH}\right)$. The swab technique was used for 5 seconds according to the ASTM E407 standard [10].

\section{Results and Discussion}

\subsection{Microstructure Observations prior to Testing}

The microstructures of INCONEL 617 in three conditions (AS, AG, and SO) are shown in Fig. 2. For the AS specimen, the microstructure revealed the equiaxed austenitic grain structure and a band structure of the precipitate phase along both the grain boundaries and in the grain interior. In the AG specimen, the microstructure showed larger grains with large particles identified as Mo-rich $\mathrm{M}_{6} \mathrm{C}$ carbide and small-size precipitate particles identified as $\mathrm{Cr}$-rich carbides $\left(\mathrm{M}_{23} \mathrm{C}_{6}\right.$ carbide). These particles appeared both along the grain boundaries and grain interior for all heat treatment conditions, which conformed to a report by Gariboldi et al. (2008) [4]. In addition, other particles appeared light orange-coloured under OM and were also found with rich in Ti, C and N, which were probably Titanium carbo-nitrides Ti $(\mathrm{C}, \mathrm{N})$. Figure 2(c), the $\mathrm{SO}$ condition, showed a large grain size for austenite grains. Coarse carbide particles appeared along the grain boundaries, identified as $\mathrm{M}_{6} \mathrm{C}$ and $\mathrm{M}_{23} \mathrm{C}_{6}$. The other particle that appeared in the grain interior was $\mathrm{Ti}$ $(\mathrm{C}, \mathrm{N})$.

Table 3. Creep rupture conditions and results of INCONEL 617.

\begin{tabular}{|c|c|c|c|c|c|c|c|c|c|}
\hline \multirow[b]{2}{*}{ ID } & \multirow[b]{2}{*}{$\begin{array}{c}\text { Tempe } \\
\text { rature } \\
\left({ }^{\circ} \mathrm{C}\right)\end{array}$} & \multicolumn{4}{|c|}{$80 \%$ YS } & \multicolumn{4}{|c|}{$90 \%$ YS } \\
\hline & & $\begin{array}{l}\text { Stress } \\
(\mathrm{MPa})\end{array}$ & $\begin{array}{l}\text { Time to } \\
\text { Rupture } \\
\text { (h) }\end{array}$ & $\begin{array}{l}\text { RA } \\
(\%)\end{array}$ & LMP & $\begin{array}{l}\text { Stress } \\
(\mathrm{MPa})\end{array}$ & $\begin{array}{l}\text { Time to } \\
\text { Rupture } \\
\text { (h) }\end{array}$ & $\begin{array}{l}\text { RA } \\
(\%)\end{array}$ & LMP \\
\hline AS-1 & 700 & 274 & 466.720 & 60.94 & 27607 & 309 & 153.053 & 62.87 & 27136 \\
\hline AS-2 & 750 & 317 & 8.975 & 65.18 & 27270 & 356 & 1.730 & 79.84 & 26539 \\
\hline AS-3 & 800 & 219 & 2.682 & 90.10 & 28040 & 246 & 1.078 & 89.56 & 27615 \\
\hline AS-4 & 900 & 120 & 1.757 & 91.13 & 30437 & 135 & 0.664 & 89.06 & 29941 \\
\hline AG-1 & 700 & 384 & 47.830 & 70.89 & 26645 & 432 & 13.492 & 70.55 & 26110 \\
\hline AG-2 & 750 & 361 & 4.278 & 64.44 & 26941 & 406 & 1.367 & 66.30 & 26434 \\
\hline AG-3 & 800 & 270 & 2.424 & 82.82 & 27993 & 304 & 0.737 & 72.40 & 27438 \\
\hline AG-4 & 900 & 120 & 1.602 & 86.27 & 30390 & 135 & 0.918 & 89.11 & 30106 \\
\hline SO-1 & 700 & 173 & - & - & - & 194 & - & - & - \\
\hline SO-2 & 750 & 191 & 58.873 & 60.62 & 28106 & 215 & 33.650 & 58.72 & 27857 \\
\hline SO-3 & 800 & 180 & 8.726 & 71.55 & 28590 & 202 & 7.100 & 70.01 & 28493 \\
\hline SO-4 & 900 & 120 & 1.710 & 78.70 & 30423 & 135 & 1.591 & 74.60 & 30387 \\
\hline
\end{tabular}

\subsection{Creep-Rupture Test}

The creep rupture test parameters and results for the INCONEL 617 specimens are summarised in Table 3. The results are plotted as in Fig. 3 for both time to rupture and reduction of area (\%RA). 

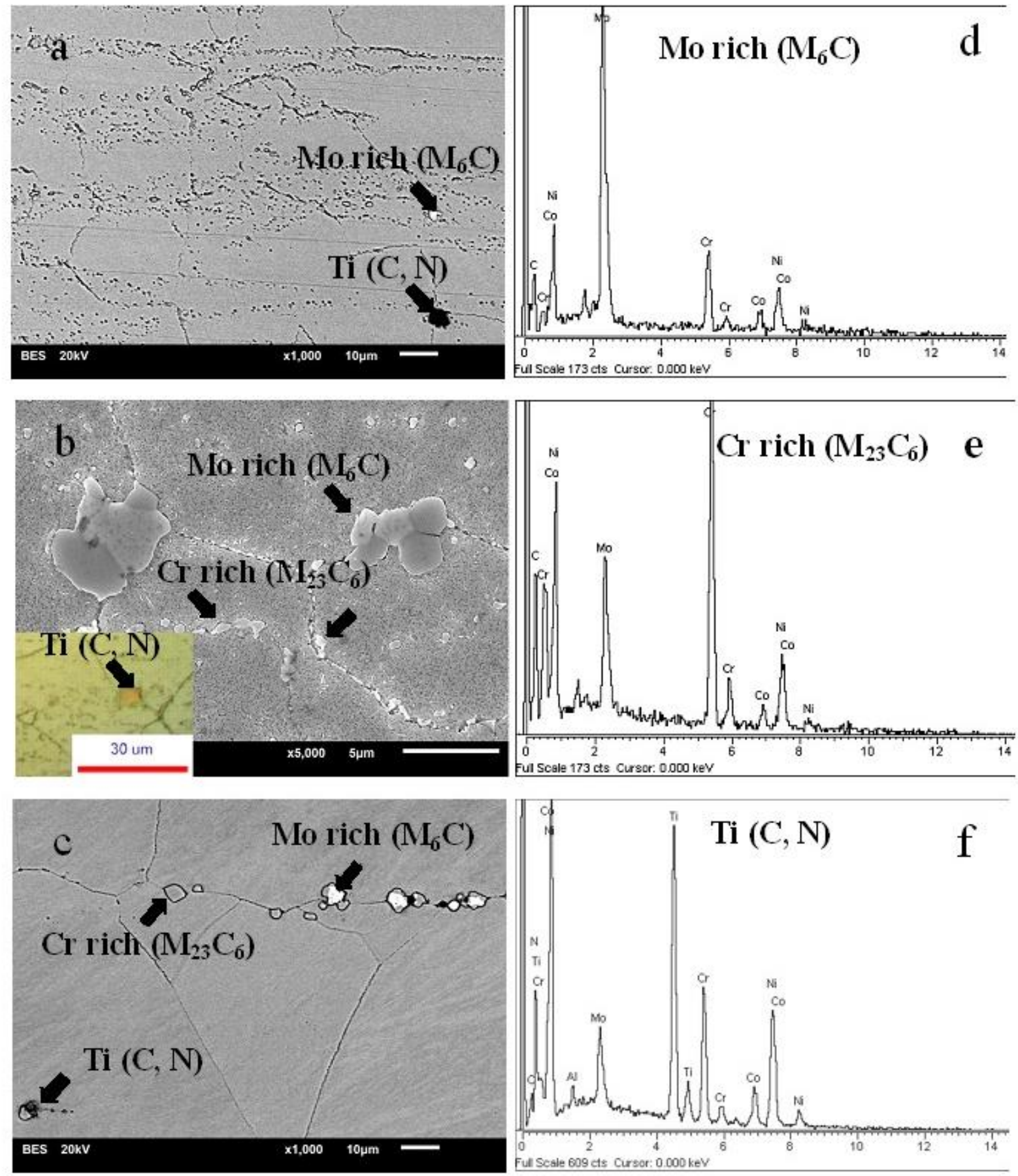

Fig. 2. Microstructure details of INCONEL 617 prior to the creep rupture test, (a) AS specimen, (b) AG specimen, (c) SO specimen, (d) to (f) the EDS results of precipitates in AG specimen. 



Fig. 3 (a) Variation of time to rupture and (b)reduction of area (\%).

At $80 \% \mathrm{YS}$ and $90 \% \mathrm{YS}$ applied stress, the time to rupture (Fig. 3(a)) for the AG condition was shorter compared to that of the AS and SO conditions. For all conditions, the time to rupture of the specimens decreased rapidly from $700^{\circ} \mathrm{C}$ to $750^{\circ} \mathrm{C}$ and then decreased gradually as the temperature increased. At higher test temperatures $\left(800^{\circ} \mathrm{C}\right.$ and $\left.900^{\circ} \mathrm{C}\right)$, the specimens failed in a short time. This was due to overtemperature resulting in overload type failure, which could be evidenced from the high reduction areas of the fracture surfaces.

For the AS condition, the \%RA (Fig. 3(b)) increased slightly from $700^{\circ} \mathrm{C}$ to $750{ }^{\circ} \mathrm{C}$ and then increased rapidly to $800^{\circ} \mathrm{C}$ and $900^{\circ} \mathrm{C}$. Meanwhile, the $\% \mathrm{RA}$ of the $\mathrm{AG}$ condition started to drop at $750^{\circ} \mathrm{C}$ and then increased as the temperature increased. The low reduction in area of the $A G$ specimens at $750^{\circ} \mathrm{C}$ indicated ductility loss of the specimens as a characteristic of creep failure. In the same way for both AS and SO, the trend of \% RA for both conditions increased rapidly from $750^{\circ} \mathrm{C}$ to $800^{\circ} \mathrm{C}$ and then flattened out, after which it continued to increase gradually as temperature increased. The high \%RA at high test temperatures $\left(800\right.$ and $\left.900^{\circ} \mathrm{C}\right)$ corresponded to the fact that overload failure could potentially occur.

Both the ductility loss and short time to rupture drop at $750^{\circ} \mathrm{C}$ were believed to be associated with the formation of $\mathrm{Cr}_{23} \mathrm{C}_{6}$ carbides at the grain boundaries. G. A. Young et al. [11] performed researches on X750, 718 and Monel ${ }^{\circledR}$ K-500 alloys and found a significant ductility loss at intermediate test temperatures. In the X-750 alloy, ductility loss corresponded to the formation of precipitates, which were partially coherent between $\mathrm{M}_{23} \mathrm{C}_{6}$-type carbide and matrix. This conformed to the IN617 in this study, in which $\mathrm{M}_{23} \mathrm{C}_{6}$ could possibly form on the microstructure during the test temperature, especially $750^{\circ} \mathrm{C}$.

The relationship between stress, temperatures, and time to rupture for each material was created using the Larson-Miller Parameter (LMP), as shown in Fig. 4. The calculations are expressed as follows:

$$
\begin{aligned}
L M P & =T(K)(C+\log t) \\
\sigma & =a L M P+b
\end{aligned}
$$


where $\mathrm{T}$ is the test temperature in Kelvin, $\mathrm{t}$ is the time to rupture in hours, $\mathrm{C}$ is a constant assumed to be 25.7, $\sigma$ is the applied stress in $\mathrm{MPa}$, $\mathrm{a}$ is the constant and $\mathrm{b}$ is the intercept.

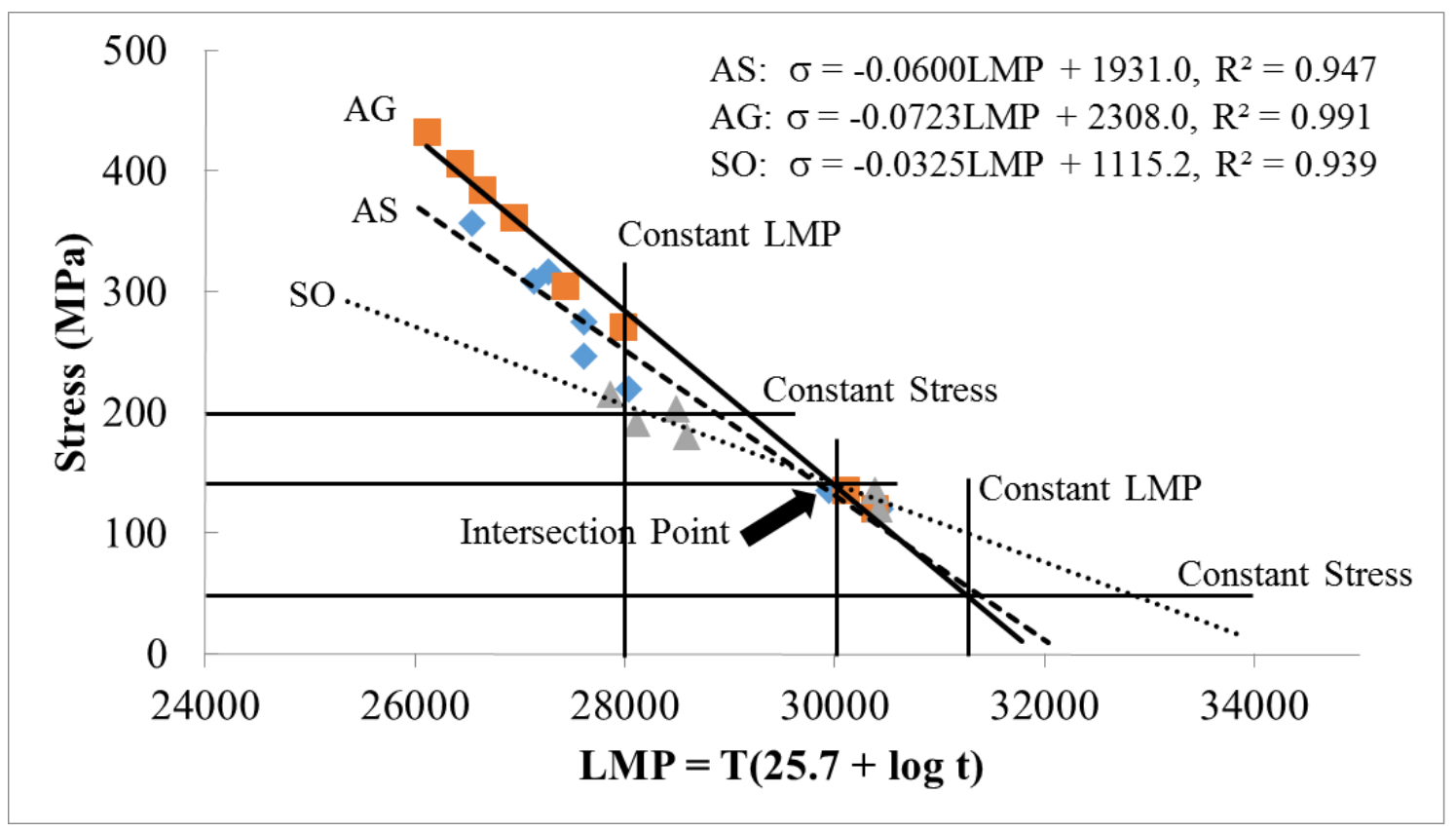

Fig. 4 Larson-Miller parameter plot for INCONEL 617 in as-received (AS), aged (AG) and solution conditions (SO).

Figure 4 illustrates the relationship between applied stress and LMP. This could be used for prediction of Larson-Miller parameters at a given stress. Subsequently, the calculation from LMP can be derived to obtain time to rupture at given temperatures by using Eq. (1) and (2), which are also shown in Fig. 4. The results from experiments exhibited good correlation, which can be confirmed by $\mathrm{R}^{2}$ values of $0.947,0.991$ and 0.939 for AS, AG and SO conditions, respectively. Interestingly, there was a zone of intersection among heat treatment conditions. This indicated that test specimens could behave differently according to the level of applied stress.

At a high stress level such as $200 \mathrm{MPa}$, the rupture life of the aged specimen was noticeably longer than the AS and SO specimens. At an LMP value of 28,000, the aged specimen resisted load bearing better than the AS and SO specimens. This was because the aged specimens had more $\gamma^{\prime}-\mathrm{Ni}_{3}$ (Al, Ti) precipitate, which resulted in high temperature strength and creep strength [12-13].

On the other hand, the rupture behaviour changed significantly compared to high applied stress, as shown at the low stress level on the right-hand side of the intersection in Fig. 4. For example, the rupture life of the SO specimen was significantly longer compared to those of the AS and AG specimens at $50 \mathrm{MPa}$. This was in contrast, for example at LMP $=31,200$, to the SO specimens that had longer creep life than the as-received and aged specimens. This resulted from discrete precipitation of $\mathrm{M}_{23} \mathrm{C}_{6}$ carbides along the grain boundaries, which improved the creep strength by restricting grain boundary sliding [14].

Comparing the allowable design stresses from ASME II-Part D-2010 (see UG-23) [15], for example, the AG-750-80YS specimen could use the maximum allowable designed stress, as indicated by ASME at around 50.4 MPa. However, the creep test in this study showed that the specimen at low test temperature failed at $360.99 \mathrm{MPa}$, which was about 7.16 times higher. On the other hand, the maximum allowable designed stress at $900^{\circ} \mathrm{C}$ for the specimen tested at higher temperature, such as specimen AG-900-80YS, would be $12.5 \mathrm{MPa}$ from ASME, in which the specimen was tested at $120 \mathrm{MPa}$ or about 9.63 times higher. Although in this study would apply stress higher than allowable stress, it had showed the evidence of macro-plastic deformation on the tested specimens, resulting in failure occurred into creep and overload mode. 


\subsection{Microstructure Observations after the Creep Rupture Test}

Figure 5 shows typical OM morphologies for the creep specimens. The AG-80YS specimens showed precracks near the failure location, which were believed to initiate and propagate along the grain boundaries. On the other hand, there was very little evidence of pre-cracks at the grain boundaries of the other heat treatment specimens. In addition, there was microscale plastic deformation for the grains of all types of specimens at high tested temperatures, supporting the evidence of the combination of overload failure.
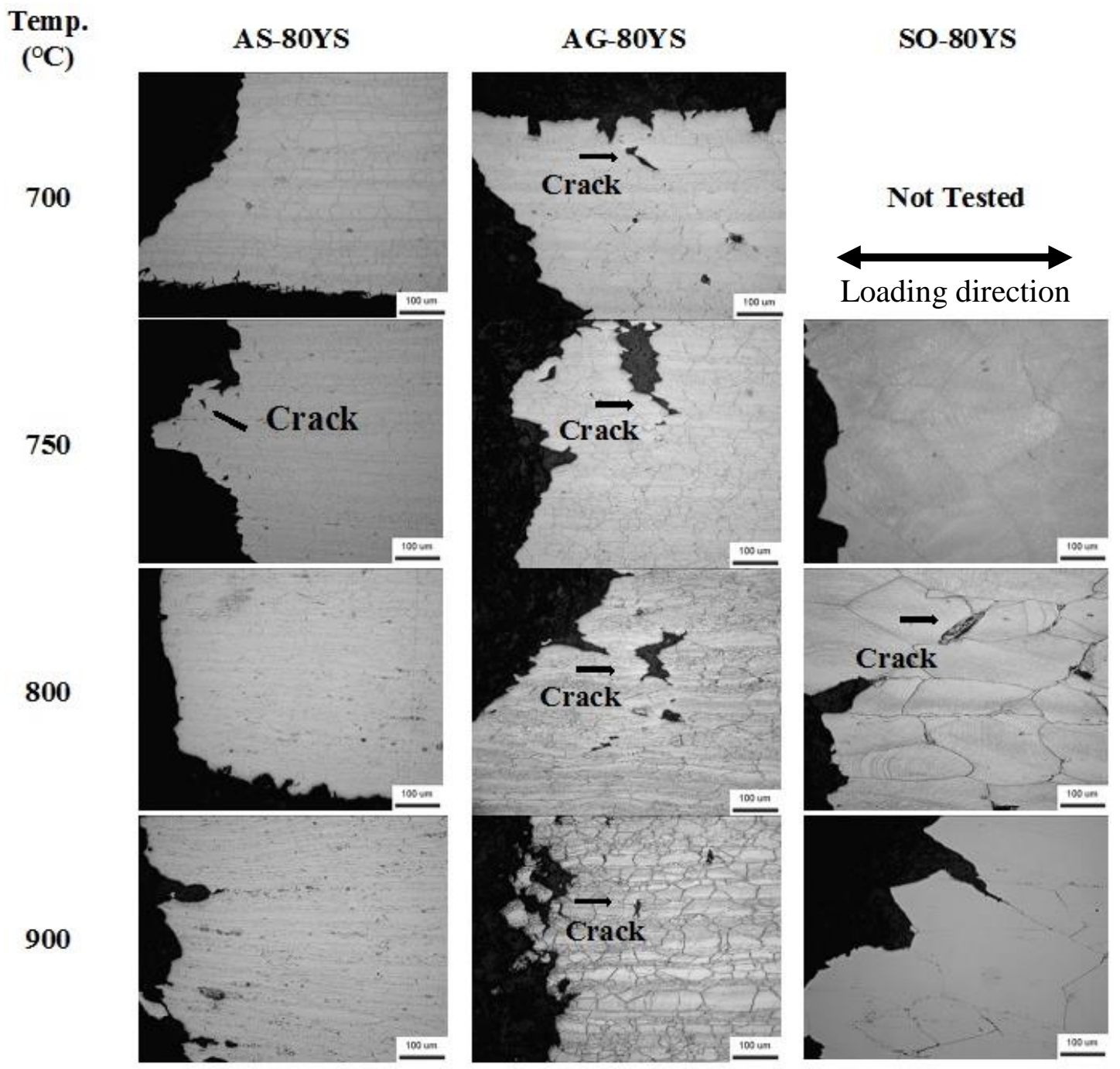

Fig. 5 Microstructure of creep rupture test samples at high magnification for INCONEL 617.

Figure 6 shows SEM micrographs of the creep rupture specimens at $80 \% \mathrm{YS}$ for all heat treatment conditions, which display pre-cracks, propagated along the grain boundaries. Some of the pre-cracks were adjacent to coarse grain boundary carbides (Fig. 6(a)) for the as-received specimen. In the same way, Figs. 6(b) and 6(c) show that both the aged and solutionised specimens also had micro cracks, micro voids, Crrich $\left(\mathrm{M}_{23} \mathrm{C}_{6}\right)$, and Mo-rich $(\mu)$ along the grain boundaries, similar to DuPont et al. [16-17]. This showed that the pre-cracks were initiated adjacent to the grain boundary carbides, resulting in lower adhesion of the grains and subsequent ductility drop with grain boundary sliding, especially at a test temperature of $750^{\circ} \mathrm{C}$. EDS microanalyses in Figs. 6(d) and 6(e) were confirmed with two type of precipitates, (i) Cr-rich carbides $\left(\mathrm{M}_{23} \mathrm{C}_{6}\right.$ carbide) and (ii) Mo-rich $(\mu)$ carbide, which was the same as reported by Wu et al. (2008) [18]. The $\gamma^{\prime}-\mathrm{Ni}_{3}$ (Al, Ti) occurred during the creep rupture test, which were also identified by analysis of the XRD [19]. The XRD results are shown in Fig. 7. The plot revealed a peak corresponding to the $\gamma^{\prime}-\mathrm{Ni}_{3} \mathrm{Al}$ such as (111), (200), (220), (330) and (222) [20]. Therefore, it was possible that the analysed precipitate would consist of $\gamma^{\prime}-\mathrm{Ni}_{3} \mathrm{Al}$ in creep specimens of $\mathrm{AS}, \mathrm{AG}$, and $\mathrm{SO}$ conditions. 

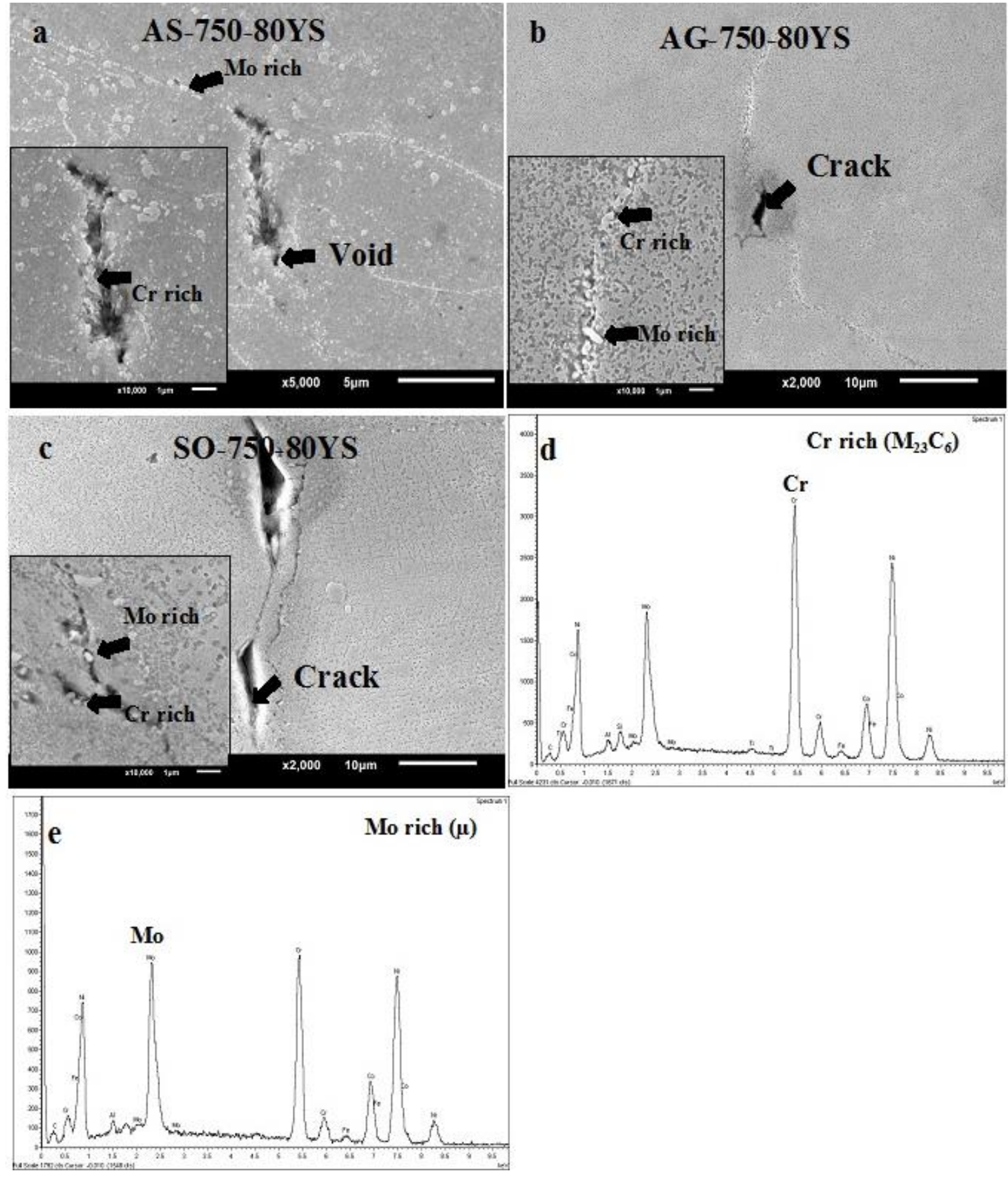

Fig. 6 Typical metallographic microstructure (SEM): (a) Specimen AS-750-80YS, SEM images showing a crack and voids at grain boundaries and intragranular carbides; (b) Specimen AG-750-80YS, SEM images showing details of a grain boundary decorated with Cr-rich $\left(\mathrm{M}_{23} \mathrm{C}_{6}\right)$ carbides and Mo-rich $\left(\mathrm{M}_{6} \mathrm{C}\right)$; (c) Specimen SO-750-80YS, SEM images showing a crack with Mo-rich $(\mu)$ carbide and Cr-rich $\left(\mathrm{M}_{23} \mathrm{C}_{6}\right)$ at the grain boundaries; (d) and (e) EDS results of Mo-rich ( $\mu$ ) and Cr-rich $\mathrm{M}_{23} \mathrm{C}_{6}$. 


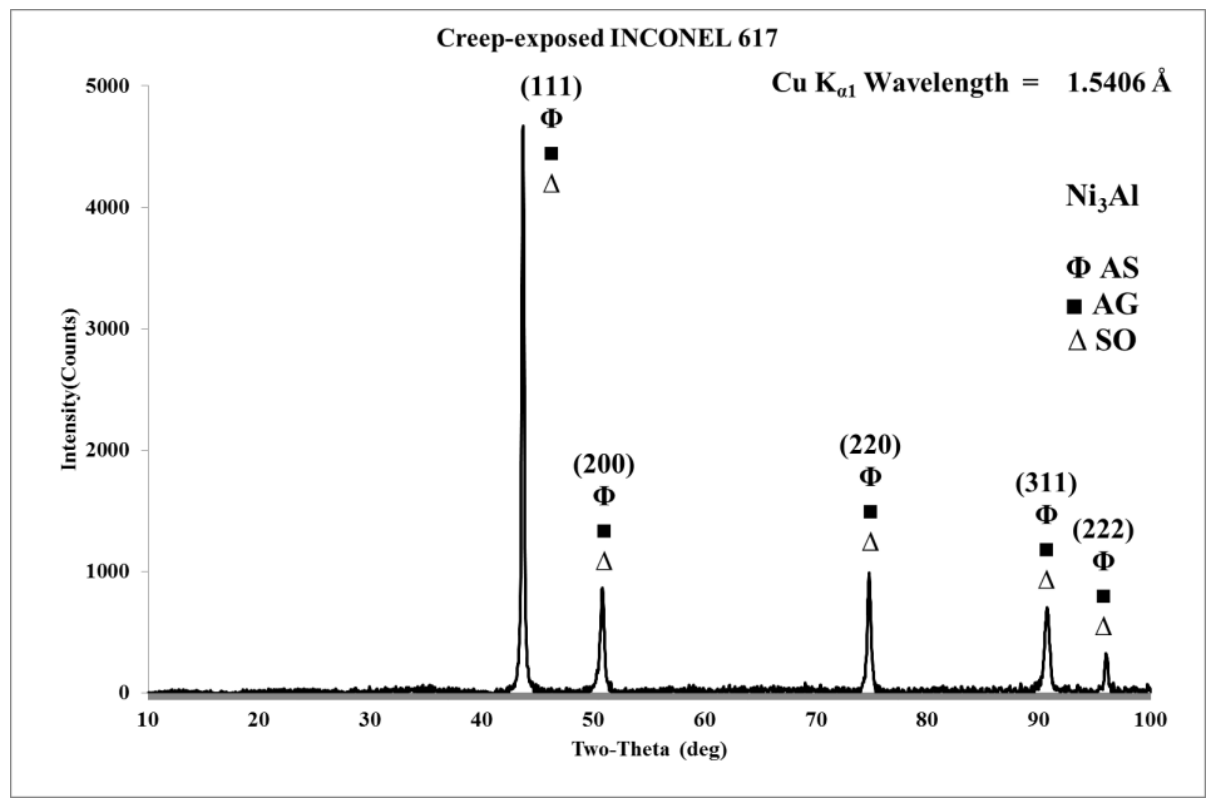

Fig.7. X-Ray diffraction spectrum (Intensity versus 2Ө) of creep-exposed INCONEL 617 alloy. XRD peaks identified with $\gamma^{\prime}-\mathrm{Ni}_{3} \mathrm{Al}$ phase present in the alloy.

\section{Conclusions}

In this investigation, the accelerated creep rupture test was used to study the creep properties of INCONEL 617 under various heat treatment conditions (as-received, aged and solutionised).

Based on the results of testing, the following inferences are made:

1. Time to rupture for the aged condition was the shortest, followed by the as-received and solutionised conditions.

2. The aged conditions showed a drop in reduction area or ductility loss at around $750^{\circ} \mathrm{C}$, which was associated with the formation of $\mathrm{Cr}_{23} \mathrm{C}_{6}$-type carbides at the grain boundaries.

3. For the as-received condition, the results of $\% \mathrm{RA}$ slightly increased from $700^{\circ} \mathrm{C}$ to $750^{\circ} \mathrm{C}$ and then rapidly increased to $800^{\circ} \mathrm{C}$ and $900^{\circ} \mathrm{C}$. The solutionised condition showed the same trend.

4. The Larson Miller curve for all heat treatment conditions showed the zone of an intersection. This could indicate the change of failure behaviour from high to low applied stress levels or from overload failure to creep failure, respectively.

5. The microstructure under OM micrograph after the creep rupture test showed pre-cracks near the failure location. High test temperatures showed macro plastic deformations at the grains as evidence of overload failure, while micro voids and Cr-rich $\left(\mathrm{M}_{23} \mathrm{C}_{6}\right)$ along the grain boundaries in lower test temperatures showed evidence of creep failure.

\section{Acknowledgements}

The authors extend their gratitude to the Scholarship [Contract No.: NUI-RC-33-20-54-040D] of NSTDAUniversity-Industry Research Collaboration: NUI-RC, MTEC and ISTRS, King Mongkut's University of Technology Thonburi (KMUT'T) for providing the budget for this research.

\section{References}

[1] M. S. Rahman, G. Priyadarshan, K. S. Raja, C. Nesbitt, and M. Misra, "Characterization of high temperature deformation behavior of Inconel 617," Mech. Mater, vol. 41, no. 3, pp. 261-270, 2009.

[2] M. Akbari-Garakani, and M. Mehdizadeh, "Effect of long-term service exposure on microstructure and mechanical properties of Alloy 617," Materials \& Design, vol. 32, no. 5, pp. 2695-2700, 2011.

[3] S. Chomette, J. M. Gentzbittel, and B. Viguier, "Creep behaviour of as received, aged and cold worked INCONEL 617 at $850^{\circ} \mathrm{C}$ and $950^{\circ}$ C," J. Nucl. Mater., vol. 399, no. 2, pp. 266-274, 2010. 
[4] M. Cabibbo, E. Gariboldi, S. Spigarelli, and D. Ripamonti, "Creep behavior of INCOLOY alloy 617," J. Mater. Sci., vol. 43, no. 8, pp. 2912-2921, 2008.

[5] A. Ghatak and P. S. Robi, "Modification of Larson-Miller parameter technique for predicting creep life of materials," Trans Indian Inst Met, vol. 69, no. 2, pp. 579-583, 2016.

[6] V. Knezevic, A. Schneider, and C. Landier, "Creep behaviour of thick-wall alloy 617 seamless pipes for $700^{\circ} \mathrm{C}$ power plant technology," Procedia Engineering, vol. 55, pp. 240-245, 2013.

[7] W. L. Mankins, J. Hosiser, and T.H. Bassford, "Microstructure and phase stability of Inconel alloy 617," Metallurgical Transactions, vol. 5, no. 12, pp. 2579-2590, 1974.

[8] P. J. Ennis, W. J. Quadakkers, and H. Schuster, "The effect of selective oxidation of chromium on the creep strength of alloy 617," Le Journal de Physique IV, vol. 3, no. C9, pp. 979-986, 1993.

[9] Standard Practice for Conducting Creep, Creep-Rupture, and Stress-Rupture Tests of Metallic Materials, ASTM E139, 1989.

[10] Standard Practice for Micro-etching Metals and Alloys, ASTM E407, 1993.

[11] G. A. Young, T. E. Capobianco, M. A. Penik, B. W. Morris, and J. J. Mcgee, "The mechanism of ductility dip cracking in nickel-chromium alloys," Welding J., vol. 87, no. 2, pp. 31-43, 2008.

[12] W. Liu, F. Lu, R. Yang, X. Tang, and H. Cui, "Gleeble simulation of the HAZ in Inconel 617 welding," J. Mater. Process. Tech., vol. 225, pp. 221-228, 2015.

[13] N. Phuraya, I. Phung-On, H. Terasaki, and Y. Komizo, "Direct observation of liquation in Ni-base Superalloy by using Confocal Laser Scanning Microscopy," Key Engineering Materials, vol. 658, pp. 3641, 2015.

[14] R. Krishna, H. V. Atkinson, S. V. Hainsworth, and S. P. Gill, "Gamma prime precipitation, dislocation densities, and TiN in creep-exposed Inconel 617 alloy," Met. Trans. A, vol. 47, no. 1, pp. 178-193, 2016.

[15] ASME Boiler and Pressure Vessel Code, Section II, Part D, Properties, Table 1B, ASME, New York, NY, pp. 214-217, 2010.

[16] J. N. DuPont, J. C. Lippold, and S. D. Kiser, "General influence of alloying additions," in Welding Metallurgy and Weldability of Nickel-Base Alloys, $1^{\text {st }}$ ed. New Jersey: John Wiley \& Sons, 2009, pp. 16-20.

[17] ASM Specialty Handbook, 1sted, Materials Park, OH, 2000, pp. 79-83.

[18] Q. Wu, H. Song, R. W. Swindeman, J. P. Shingledecker, and V. K. Vasudevan, "Microstructure of long-term aged IN617 Ni-base superalloy," Met. Trans. A. vol. 39, no. 11, pp. 2569-2585, 2008.

[19] R. Krishna, S. V. Hainsworth, S. P. A. Gill, A. Strang, and H. V. Atkinson, "Topologically closepacked $\mu$ phase precipitation in creep-exposed inconel 617 alloy," Met. Trans. $A$, vol. 44, no. 3, pp. 1419-1429, 2013.

[20] A. M. Trostianchyn, I. I. Bulyk, I. V. Trostianchyn, S. I. Mudry, and V. M. Davydov, "Phase transformations in $\mathrm{La}_{0.5} \mathrm{Nd}_{0.5} \mathrm{Ni}_{5-\mathrm{x}} \mathrm{Al}_{\mathrm{x}}-\mathrm{H}_{2}$ system," Rev.Adv.Mater.Sci.(RAMS), vol. 23, no. 2, pp. 119$125,2010$. 